Arthritis \& Rheumatism (Arthritis Care \& Research)

Vol. 59, No. 2, February 15, 2008, pp 297-298

(C) 2008, American College of Rheumatology

LETTERS

DOI 10.1002/art.23349

\section{Epidemiology of systemic lupus erythematosus in the United Kingdom: comment on the article by Somers et al}

\section{To the Editors:}

We read with interest the article by Somers et al in Arthritis Care \& Research reporting on the incidence of systemic lupus erythematosus (SLE) in the UK (1). This study suggests a markedly higher incidence rate for SLE than we found using the same database (2) and we imagine your readers will be interested in understanding how these differences arose.

Various methodologic issues need to be considered when estimating the incidence of a chronic relapsingremitting disease such as SLE using a clinical database (3). One such issue is the duration for which SLE patients can be in remission. To enable the distinction between incident (new) and prevalent (pre-existing) cases, the investigator needs to be confident that the first record encountered in the database is actually the first occurrence of the disease for that patient. To account for this, a minimum period of registration before diagnosis needs to be defined. Lewis et al (4) described how this minimum period of time will differ between acute, chronic, and neoplastic outcomes, and concluded that patients' "early portion of follow-up" should be excluded, with the duration of this followup portion varying by disease and being longest for chronic recurrent diseases. We chose to require $\geq 3$ years' prior data without any record of SLE before we accepted the SLE patients identified as likely incident cases, rather than patients who were having an SLE flare or relapse. For the entire study population, therefore, the first 3 years of data did not contribute to the denominator in calculating the incidence rates. The choice of 3 years was based on the reported mean \pm SD duration of remission for patients with SLE, which varies between studies but is generally reported to be $2.3 \pm 1.1$ years (5). Somers et al required $\geq 1$ years' worth of data before first diagnosis (1). If 1 year is indeed enough, then the resulting incidence rates should be the same as a 3-year period, since the amount of persontime discarded from the study is accounted for in the calculation of the denominator. However, if 1 year is not enough, then this will have led to the inclusion of prevalent cases in the study by Somers et al, resulting in overestimated incidence rates.

From our understanding of the article, Somers and colleagues included patients based on the identification of relevant medical codes (1), which presents an additional problem. In our study we required supporting evidence for a diagnosis such as relevant drug treatment, a diagnosis made in a hospital (we assumed this would have been by a rheumatologist), and/or meeting $\geq 4$ American College of Rheumatology (ACR) criteria $(2,6)$. In contrast to conduct- ing automated searches only, we manually reviewed $>4,500$ potential cases initially identified. For the largest part of the database, free text comments were available with diagnoses, which informed our decision as to whether the potential case was incident or not and whether the patient was an SLE patient or not. For instance, free text recorded together with an SLE diagnosis could state "excluded." At this stage, we excluded many patients we believed to have disseminated or cutaneous forms rather than systemic-type lupus, prevalent rather than incident, and rheumatoid arthritis rather than SLE.

We believe that as a result of our requirement for supporting evidence of a diagnostic code combined with our manual review of the full patients' records, we excluded more cases than we would have if we had carried out the research in the same way as Somers et al. We believe the study by Somers and colleagues was at a higher risk of including prevalent SLE cases and those that were not actually SLE patients. This will have led to overestimated rates.

Corinne de Vries, MA, MSc, PhD, FRSM

Alison Nightingale, $\mathrm{PhD}$

Richard Farmer, MB, BS, PhD, FFPHM

University of Surrey

Surrey, UK

1. Somers EC, Thomas SL, Smeeth L, Schoonen MW, Hall AJ. Incidence of systemic lupus erythematosus in the United Kingdom, 1990-1999. Arthritis Rheum 2007;57:612-8.

2. Nightingale AL, Farmer RD, de Vries CS. Incidence of clinically diagnosed systemic lupus erythematosus 1992-1998 using the UK General Practice Research Database. Pharmacoepidemiol Drug Saf 2006;15:656-61.

3. Nightingale AL, Farmer RD, de Vries CS. Systemic lupus erythematosus prevalence in the UK: methodological issues when using the General Practice Research Database to estimate frequency of chronic relapsing-remitting disease. Pharmacoepidemiol Drug Saf 2007;16:144-51.

4. Lewis JD, Bilker WB, Weinstein RB, Strom BL. The relationship between time since registration and measured incidence rates in the General Practice Research Database. Pharmacoepidemiol Drug Saf 2005;14:443-51.

5. Barr SG, Zonan-Nacach A, Magder LS, Petri M. Patterns of disease activity in systemic lupus erythematosus. Arthritis Rheum 1999;42:2682-8.

6. Tan EM, Cohen AS, Fries JF, Masi AT, McShane DJ, Rothfield $\mathrm{NF}$, et al. The 1982 revised criteria for the classification of systemic lupus erythematosus. Arthritis Rheum 1982;25: 1271-7.

DOI 10.1002/art.23350

\section{Reply}

\section{To the Editors:}

We thank de Vries et al for their interest in our study and reiterating for the readers that their prior analysis of General Practice Research Database (GPRD) data yielded a lower in- 
cidence estimate of SLE compared with our findings (1). An additional cause of difference to those they mentioned is that we standardized for age and they did not. The difference in estimates underscores the importance of a thorough understanding of the complexities of both the GPRD and SLE when analyzing and interpreting results based on this data set.

An important distinction between these 2 studies is that, as detailed in our article, our group conducted an analysis in accordance with the published methodology of Lewis et al (2) in order to determine the appropriate analysis time window to differentiate between prevalent and incident cases. Based on our empirical findings, we determined that patients who registered with a general practitioner (GP) after the GP contributed data to the GPRD needed a minimum of 1 year of followup in order to be eligible for the analysis. In contrast, Nightingale et al (1) made a decision to exclude the first 3 years of followup for all patients. They justified their choice of a 3-year window because in their understanding the "average duration of remission for SLE patients" is mean \pm SD $2.3 \pm 1.1$ years, based on findings published by Barr et al on SLE disease activity patterns from the Hopkins Lupus Cohort (3). However, the study by Barr et al actually showed that only a minority of SLE person-years were characterized by a "long quiescent" pattern of disease activity ( $\sim 16 \%)$, with remaining persontime classified as "chronic active" or "relapsing-remitting," which by definition involves disease activity during a given year. The average remission duration only applies to the "long quiescent" fraction of person-time. Moreover, it is unclear how even an accurate summary measure for the average length of remission would translate into a meaningful time window for the differentiation of prevalent and incident cases, since the standard of care for SLE requires medical followup during apparent quiescent periods to enable detection of subclinical disease (e.g., renal involvement). Use of a long exclusion period can further introduce bias if patients with followup of $>3$ years differ systematically from those with shorter followup.

As we discussed in our article, a limitation of the GPRD is that data related to ACR criteria for SLE, including autoantibody profiles, are not uniformly available, i.e., the lack of such data should not be confused with a negative result. Also, certain therapeutics (e.g., cyclophosphamide) that are prescribed by hospital consultants rather than GPs are not recorded in the GPRD. Nevertheless, Nightingale et al included ACR criteria or prescriptions for medications such as cyclophosphamide as part of their case definition. However, the application of ACR criteria (assuming it was a valid approach in this setting) versus physician diagnosis could indeed account for differences in incidence estimates, since the classification criteria have limited sensi- tivity when applied to external populations $(<85 \%)$, as opposed to the initial test population $(4,5)$. For this reason, efforts are underway in the SLE community to develop a set of criteria that performs better.

We have chosen to use standard definitions that can apply to the whole data set. We believe that there is potential bias when criteria, whether ACR or free text, can only be applied to a proportion, and often a small proportion, of the database.

A final point worth recapitulating from our article is that as external validation of our methodology, we compared our region-specific incidence estimates with those from 2 active surveillance studies based in the same geographic regions, yielding remarkably similar findings (and within the confidence intervals) to those independent studies. We estimated an age-adjusted incidence (per 100,000) of 3.56 for the West Midlands (similar to 3.8 published for Birmingham [6]) and 4.37 for Trent (similar to 4.0 published for Nottingham [7]).

In summary, we believe that the consistent methodology we used is likely to have resulted in more accurate estimates than those proposed by Nightingale et al, as indicated by the external validity.

Emily C. Somers, PhD, ScM

University of Michigan, Ann Arbor

Sara L. Thomas, MB, BS, MSc, $\mathrm{PhD}$

Liam Smeeth, MBChB, MRCGP, MSc, PhD

W. Marieke Schoonen, PhD, MSc

Andrew J. Hall, MB, BS, MSc, PhD

London School of Hygiene and Tropical Medicine

London, UK

1. Nightingale AL, Farmer RD, de Vries CS. Incidence of clinically diagnosed systemic lupus erythematosus 1992-1998 using the UK General Practice Research Database. Pharmacoepidemiol Drug Saf 2006;15:656-61.

2. Lewis JD, Bilker WB, Weinstein RB, Strom BL. The relationship between time since registration and measured incidence rates in the General Practice Research Database. Pharmacoepidemiol Drug Saf 2005;14:443-51.

3. Barr SG, Zonana-Nacach A, Magder LS, Petri M. Patterns of disease activity in systemic lupus erythematosus. Arthritis Rheum 1999;42:2682-8.

4. Somers EC, Marder W, Lewis EE, Shaltis D, Cagnoli PC, VanHuysen C, et al. Sensitivity and specificity of the ACR and Boston Weighted classification criteria for SLE [abstract]. Arthritis Rheum 2006;54 Suppl 9:S428-9.

5. Tan EM, Cohen AS, Fries JF, Masi AT, McShane DJ, Rothfield NF, et al. The 1982 revised criteria for the classification of systemic lupus erythematosus. Arthritis Rheum 1982;25:1271-7.

6. Johnson AE, Gordon C, Palmer RG, Bacon PA. The prevalence and incidence of systemic lupus erythematosus in Birmingham, England: relationship to ethnicity and country of birth. Arthritis Rheum 1995;38:551-8.

7. Hopkinson ND, Doherty M, Powell RJ. The prevalence and incidence of systemic lupus erythematosus in Nottingham, UK, 1989-1990. Br J Rheumatol 1993;32:110-5. 